\title{
The Overall Foresight Model that Focuses on Consensus Forming
}

\author{
Benjamin Yuan ${ }^{1}$, Tsai-Hua Kang ${ }^{1,2}$,Chien Ching Chang ${ }^{1}$ \\ ${ }^{1}$ Institute of Management of Technology of National Chiao Tung University, Taiwan, R.O.C \\ ${ }^{2}$ Department of Computer and Communication Engineering of De Lin Institute of Technology, Taiwan, R.O.C
}

\begin{abstract}
Due to global competition and rapid technological advancement, foresight has become an important method of formulating technological policies. Consensus forming is one of the benefits of the foresight procedure as it allows the society to effectively understand a technology's characteristics during its initial developmental stage. Also, foresight effectively guides the development of a technology, eliminating the dilemma of being unable to manage the technology's future influences. Focusing on consensus forming, this study analyzes foresight through different stages: a macro model that focuses on consensus forming has been proposed in this study in order for us to understand the influence of different factors on foresight planning. The content of consensus forming may include areas such as the possible future, the beneficial future, the preferable future, the current action plan, and its development and promotion.
\end{abstract}

\section{FOREWORD}

Since the 1990s, the rapid advancement of technology and globalization have brought forth great impact upon different nations' economic development. National policies, especial technological policies, no longer adopt a passive style of management but an active method of planning for the sake of better resource utilization [6][11][16].

Martin and Johnston [10] believe that there are three major forces that put foresight once again under the spotlight in the 1990s and make it accepted by different nations:

(1) The pressure of competition in free market: Due to globalization, the number of competitors has increased, and a nation must compete with other competitors (or nations) that have different production costs, resulting in greater competitive pressure. For example, Japan's method of developing technologies by utilizing the entire nation's resources has put a lot of pressure in other nations. Therefore, innovations in knowledge-based industries and the service sectors have become more important than before. Facing this kind of pressure, how the government reacts in terms of science and technological applications becomes more significant.

(2) Governmental expenditures in industrialized nations: As the population ages, more social benefits are needed, and each expense must be explained and proven necessary. As the cost of technological development becomes higher, no country is able to pursue all the opportunities for technological development. Under democratic budgeting, technology related budget must also follow the same rules. Technological foresight provides a mechanism in which different actors can participate and reach a consensus, making better connections between technological development, economy, and society.

(3) The nature of the knowledge-construction process is changing: New knowledge often focuses on the combination of "transdisciplinary" and "heterogeneity," especially in the field of applications. Just like how the industrial development requires strategic alliance, the Internet, and innovative national systems, the field of applied science also requires knowledge developers to jointly communicate, collaborate, and conduct research. Good interactions are not only needed between researchers but also between researchers and users such as governments, businesses, and individuals, and foresight is required to facilitate this kind of interactive process.

As for the order of this process, since most modern nations adopt the democratic system, the development of technological policies must reach a consensus between the stakeholders before they can be approved in the congress or other relevant organizations. Another reason for this is that the rapid changes in the environment and technologies have exceeded the government's capability. Therefore, foresight stresses on the participation and utilization of social groups in order to ensure the integrity of the policies and the support for future implementation.

\section{Collingridge's Dilemma Theory}

According to the theory proposed by Collingridge [3] that explains the process of management innovation, there are two possible conflicts:

(1) As the technological innovations, including the R\&D process, continue to develop, the space of freedom becomes smaller. As the technologies keep on advancing, many possibilities in the next stage of development get eliminated.

(2) The public will know more and more about technological innovations, especially when the R\&D process has reached the latter stages.

Collingridge's dilemma theory tries to depict that it is difficult to manage a technology's future influences. Unless a technology or an innovation has been widely used, we would not be able to understand its influence and effect. A technology that has already developed and matured is already tightly connected with a society, leaving fewer possibilities for changes. In other words, the future management of technological development involves the problems of information and authority. The problem with information is that unless a technology has been widely developed and utilized, its influence would be difficult to be predicted. The problem of authority is that after a technology has developed, it would be difficult to control or change its course of development [14].

David Collingridge has proposed that in order to solve this dilemma, we should develop a technology that is highly 
flexible and can be applied in different ways. He proposes that a technological development should quickly adapt to a society and the subscribers' different demands. However, developing this kind of technology in the actual world is very difficult since the cost of technological development and the target-oriented characteristic of innovation have reduced the flexibility of a technology in its development.

Schot [15] believes that in order to solve this problem, we need to be able to make predictions more frequently and as early as possible. A process of technological development should allow continuous learning and adjusting in order to create greater experimental flexibility. Collingridge's dilemma theory points out the serious inefficiency of the early warning effect in technological management. Since there is no sufficient knowledge and authority that can change the direction of technological development, the only thing our society can do is to improve its responsive capability [4].

Therefore, in order to solve this dilemma, the entire society needs to establish an effective understanding of a technology's future development. During the early stage of a technological development when the society and the R\&D group still enjoy intimate interactions, we would see better results in influencing the ultimate direction of a technological development since the effects of social influence would begin to take place while there is still a high degree of flexibility in the technological development.

Agrafiotis et al. [1] has pointed out that if the society can establish an effective understanding of a technology's future directions during its earlier developmental stage, the development of this technology can be effectively guided, solving the previously mentioned dilemma. Gow [5] points out that in order to respond to the challenges brought forth by this dilemma, actions in three aspects need to be conducted simultaneously: analytical, political, and normative. Analytical actions refer to understanding the dynamic of a technological development in a complicated environment and the momentum, method, and motive behind it. Political actions refer to understanding the composition, participation, and intervention of the stakeholders in order to ensure that all appropriate perspectives have been taken into consideration. Normative actions refer to considering social values and cultural habits and their changes when a decision is suitable for a society.

\section{DIFFERENT TYPES OF FORESIGHT MODELS}

Since the 1950s (after WWII), the U.S. has started using the method of foresight as a supplement in the decision making process for the government's technological R\&D system [8]. Japan has also adopted the Delphi Method since the 1970s in order to conduct an estimation of the trend of technological development once every 5 years [12].

However, since the technique itself had low continuity, the process of making predictions of a given technology sees many limitations. Moreover, important technological developments are often the results of the integration and international exchange of each domain's own advancement. Using the prediction of a single technology as a basis for formulating policies often yields unsatisfactory results.

Therefore, since the mid-1980s, more and more people have proposed the idea of replacing "technological predictions" with making "technological foresights" [7]. Technological foresight does not focus on technologies but the perspective of "satisfying human needs" and future demands. Through a systematic process, it studies our future technological, social, and economic changes, and the results can be used for making decisions regarding technological policies or management.

Although during the operational process, the analytical methods used in making foresights are mostly derived from the methods of making technological predictions. However, the purpose of "foresight" is to be more systematic, more user-oriented, and more influential than technological predictions, rather than for understanding the technical changes in a single domain.

We can understand what foresight really is through the models proposed by different scholars. Using Gow's perspective [5], foresight models can be put into four categories: macro, analytical, political, and normative.

\section{A. Macro Aspect}

The foresight model of the macro aspect that explains the overall foresight activity helps us understand the orientation and content of foresight. In the following models, the "future cone" explains the temporal features of foresight (long-term perspective). The "foresight triangle" explains the three important elements in the foresight activity as well as their combinations. The "integrated foresight model" explains the levels and contents in the foresight study.

\section{(1) Future Cone}

Proposed by Voros [19], the future cone (see Fig. 1) mainly explains foresight's long-term perspective. He points out that foresight attempts to analyze the differences between different types of future. This cone explains that what foresight does is for us to see the future from today and to distinguish the differences in different futures. Moreover, this model also stresses that future prospects are jointly conducted by different stakeholders who identify the preferable future that is approved by the society and employ different actions plans in order to materialize the preferable future. The future can be placed in the following categories:

A. Possible Future: The future that could happen.

B. Plausible future: The future that might happen in general.

C. Probable future: The future that would happen when the given conditions remain roughly the same.

D. Preferable future: The future desired by the designer.

Foresight analysis distinguishes the differences between different kinds of future, defines a society's preferable future, and looks for the necessary actions. 


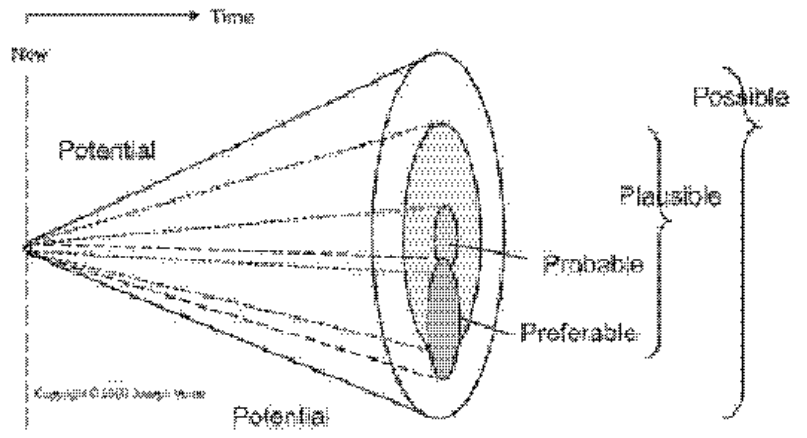

Fig. 1 Diagram of the Future Cone Source: Voros [19]

\section{(2) Foresight Triangle}

Proposed by Loveridge [9], the Foresight Triangle (see Fig. 2) explains the three necessary elements in the foresight procedure, and a good foresight activity should maintain the balance of these elements. "Expertise" refers to the ability of connecting the possible future and the existing technical challenges. "Creativity" is used to challenge the existing beliefs and investments. "Interaction" is to let stakeholders' individual predictions interact with the possible future. Placing too much weight on any of the elements would cause the foresight to fail. Too much expertise would lead to biased results, too much creativity turn the process into a science fiction, and too much interaction between participants would cause the activity to lose its focus and let the available resources go to waste.

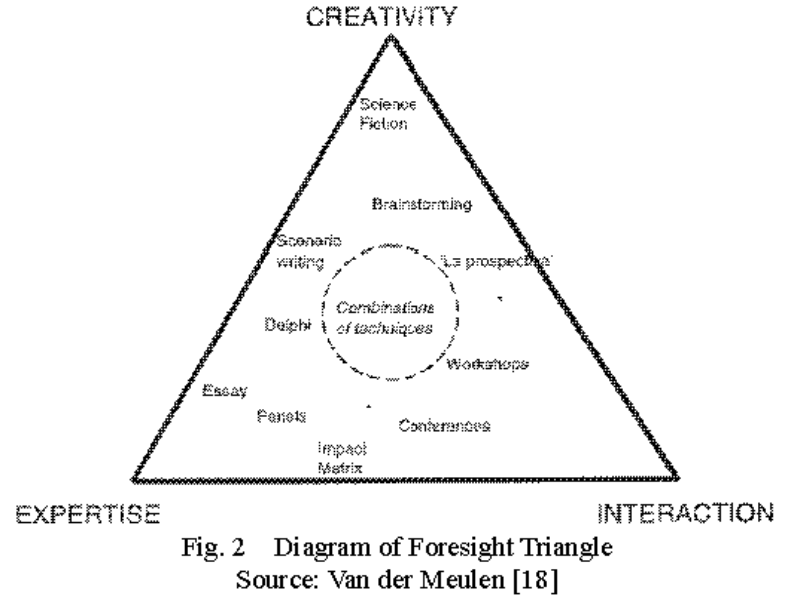

In this study, the different methods for conducting foresight have been placed in the triangle's different locations in order to express their different features. A planner can try different combinations to ensure that the foresight activity has included these three characteristics.

(3) Integrated Foresight Model

Alsan and Oner [2] have organized an Integrated Foresight Model from many literatures, including three levels and four elements that are used to explain the content of the foresight activity (see Fig. 3). The three levels are normative, strategic, and operative; the four elements are knowledge, people, system, and organization.

The Integrated Foresight Model lists foresight's important aspects, and it can be used to plan, evaluate, and explain the process. It is an important content model used to explain foresight.

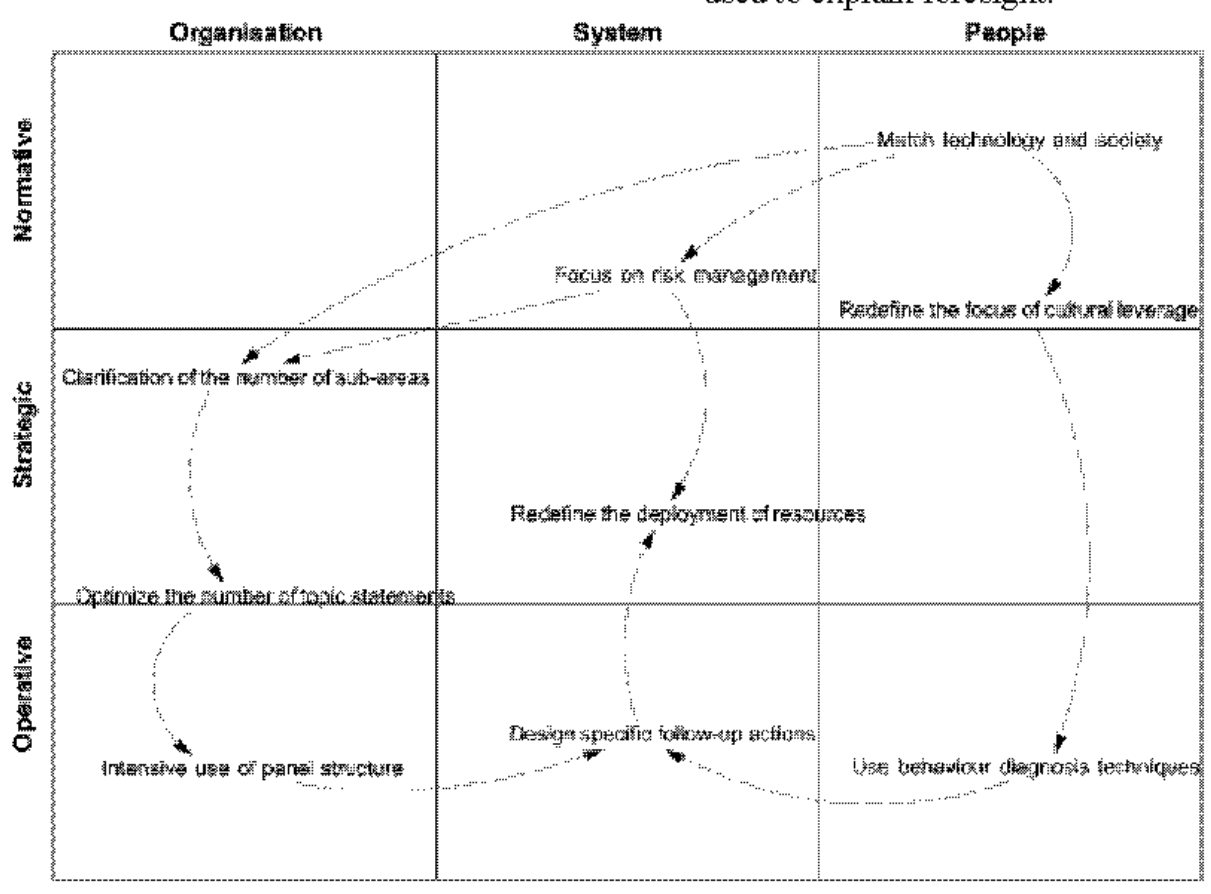

Fig. 3 Diagram of Integrated Foresight Model Source: Alsan and Oner [2] 


\section{B. Analytical Aspect Model}

The Analytical Aspect Model looks at foresight from an analytical aspect, and its main purpose is to discuss the factors that are used in analyzing the future considerations or the analytical process. It helps us understand the perspectives that we should take when we conduct foresight analysis. The factors that influence technical foresight are listed below, which explain the implementation of the Integrated Foresight Model and the two necessary forces. Technical Future Analysis categorizes different analytical methods, whereas the General Foresight Framework explains a foresight's procedures and the analytical steps.
(1) Factors that Influence Technical Foresight Tegart [17] has identified the factors that influence foresight as the "demand-pull" and the "science/technology-push" (see Fig. 4). The "science/technology-push" includes scientific and technological strengths and resource and opportunities. The "demand-pull" includes the economic, social, and environmental needs and resources. This model shows that a foresight simultaneously integrates social demands and technical supplies and looks for a junction where different perspectives can be satisfied.

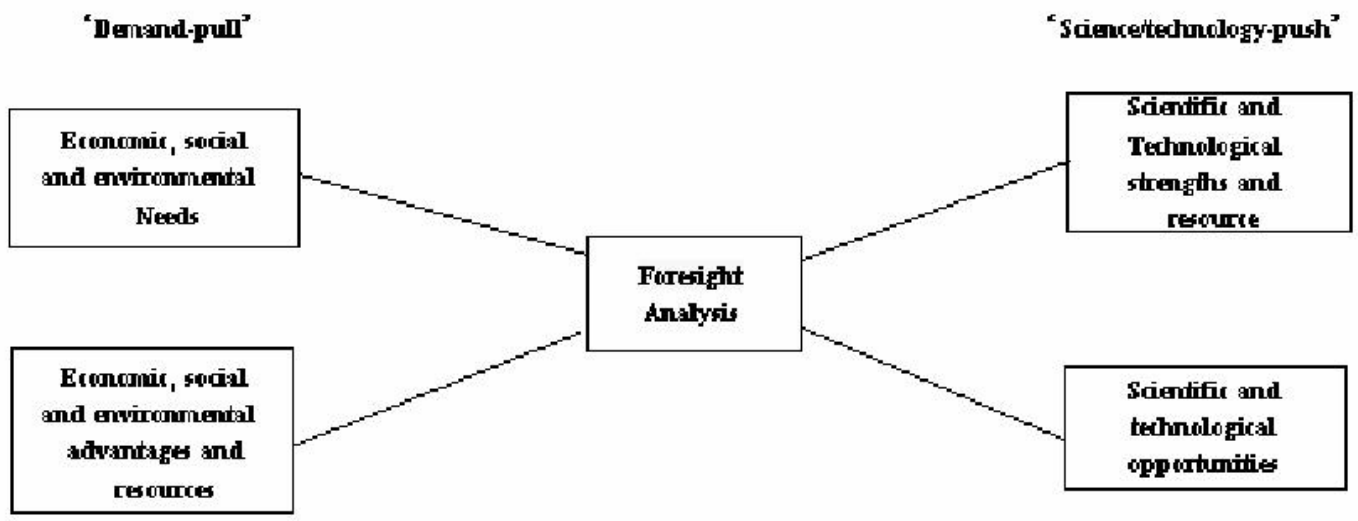

Fig. 4 Factors that Influence Foresight Analysis Source: Tegart [17]

(2) Technological Future Analysis

The method of "future analysis" proposed by Porter et al. [13] has put the methods of future research into the following categories: creativity, indicators and narrations, statistics, expert ideas, monitoring and intelligence compilation, model construction and simulation, context analysis, trend analysis, and evaluating economic policies. These categories can be quantified or qualified based on their content. Moreover, they can also be distinguished based on the explorative and normative nature. Foresight often includes different kinds of combination that match the analytical content required by the relevant policies. This model explains the content and categories of the methods available to the foresight process.

(3) General Foresight Framework

The General Foresight Framework proposed by Voro [19] explains the analytical process and common methods in the foresight process (see Fig. 5). The General Foresight Framework utilizes a strategic planning perspective that views the foresight process as a system, and the output of which needs to be transformed into an actual strategy that influences a society and the future direction of a technology. The foresight process can be divided into the 3 stages of analysis, interpretation, and prospection, which involve different methods. The General Foresight Framework explains the complexity of foresight analysis, and the entire process is consisted of different methods. Each stage focuses on different things and utilizes different methods.

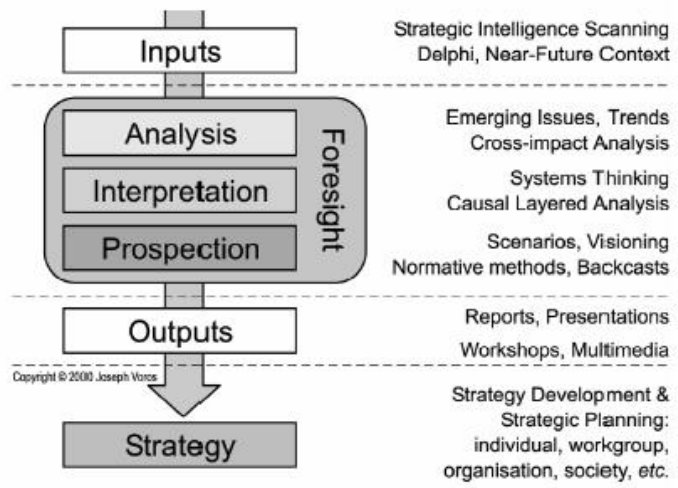

Fig. 5 Voros' General Foresight Framew ork Source: Voros [19]

\section{FORESIGHT INTEGRATION FRAMEWORK - REACHING CONSENSUS}

Foresight is about looking into the future and making a systematic observation for the sake of shaping a better future. Foresight is not limited to a single future; there can be many choices, but only one of them will happen based on the actions we take now. Technical foresight is about choosing 
the future we want and investing in the needed resources.

Based on these ideas, we have organized different foresight models and proposed a Foresight Integration Model that is focused on consensus forming. This model can be used for the planning and analysis of consensus forming that takes

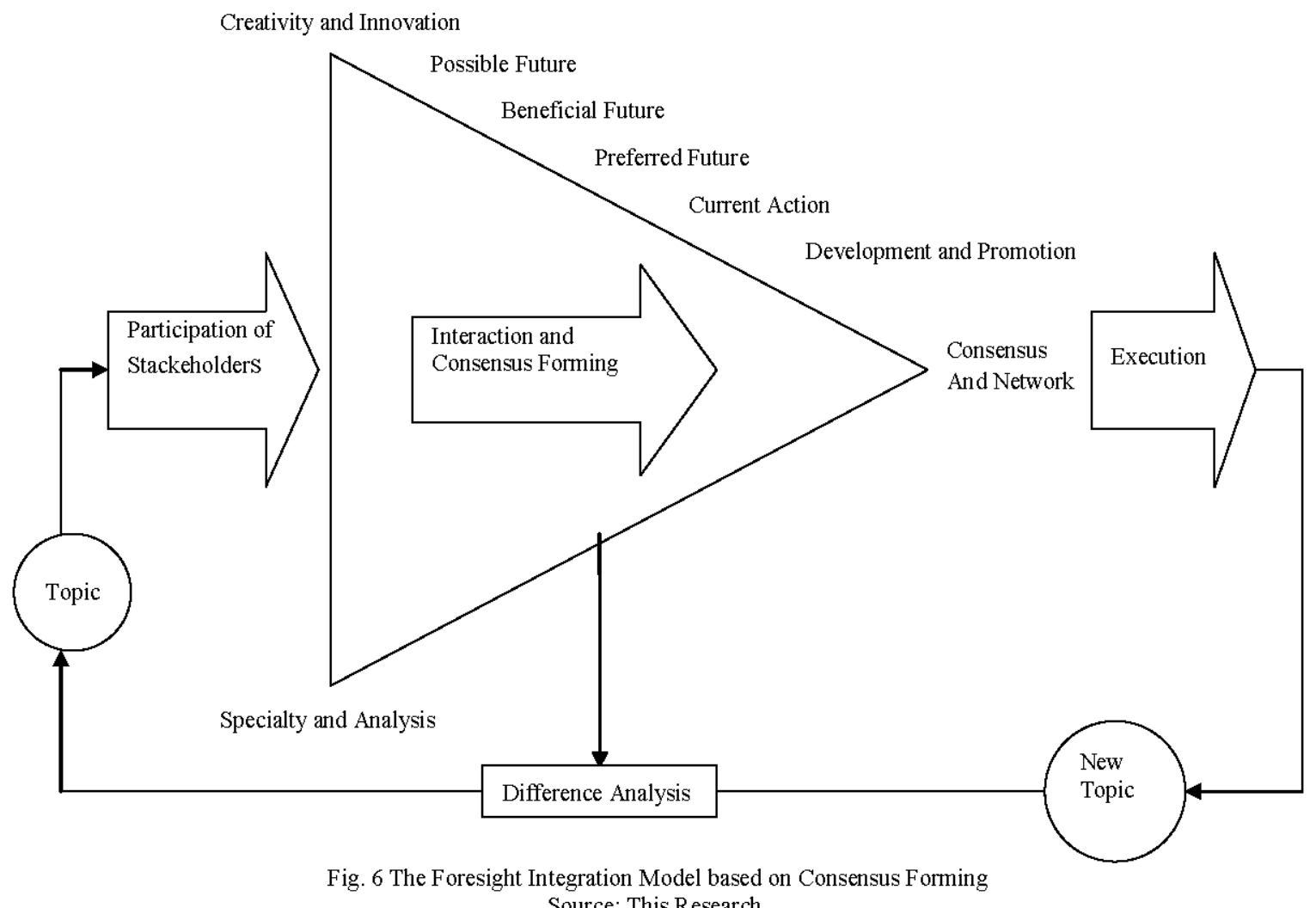

place in foresight activity. This framework has integrated analytical behaviors, political behaviors, and normative behaviors, and is an integrative framework that focuses on stakeholders' participation and consensus forming (see Fig. 6). Source: This Research.
This model is a continuous procedure that begins with a certain topic. Foresight is a topic-oriented or problem-oriented activity, and the foresight procedure only begins when stakeholders participate. The possible starting points of the foresight procedure may be the emphasis on innovation and creativity, expertise or analysis, or the combination of the first two. During the process, different groups go through discussions, analysis, and interactions before they finally reach a consensus regarding the good (preferred) future and interpersonal network. They then put the conclusion of foresight into action until new topics come up. The bottom half of the diagram is the feedback procedure, in which new topics are compared with the good (preferred) future goals. This cycle continues to go on, and the groups that continue to adjust their actions establish new consensus and norms, allowing a bright future to materialize.

Foresight analysis can be conducted from different angles. One is from an expert and analytical angle, in which data, models, and experts' opinions are used to estimate the future. The extreme end is the establishment of a model of future simulation which requires great expertise and analysis. Another angle is one from creativity and innovation, in which normative thinking or group discussions are used to discuss the future possibilities. The most extreme example is science fiction. Foresight can be initiated from either angle or from both angles. Using different methods, the process may not be a straight line; it may be a curved line in which stakeholders' consensus and network are reached via discussions.

To the researchers: This includes researchers in the field of policies or others. This model focuses on the interactions between stakeholders in the foresight process, consensus forming, and the network for pursuing the common goals. This model helps researchers analyze the less talked about political and normative aspects from a systematic perspective. Moreover, this model introduces different methods into the foresight process that facilitate the development of more practical tools for planning and solve the difficulties in planning caused by multiple methods.

\section{REFERENCES}

[1] Agrafiotis, D., Vagianou-Angelaki, D., Paschali, N., and Maina, A. (1994), "The Scenario Workshop Methodology: The case of Corfu", Sustainable Urban Living in the Coming Decades, 5-7 May 1994.

[2] Alsan, A., and Oner, M.A. (2004), "An integrated view of foresight: integrated foresight management model", Foresight, 5(2), pp. 33-45.

[3] Collingridge, D. (1980), The Social Control of Technology, London: Frances Pinter. 
[4] Eijndhoven, J.V. (1997), "Technology Assessment: Process or Product?", Technological Forecasting and Social Change, 54 (2,3), pp. 269-286.

[5] Gow, G. A. (2005), "Policymaking for Critical Infrastructure: a case study on strategic interventions in public safety telecommunications, Burlington, VT, USA: Ashgate.

[6] Grupp, H. and Linstone, H. (1999), "National technology foresight activities around the globe: resurrection and new paradigms", Technological Forecasting and Social Change, 60(1), pp. 85-94.

[7] Irvine, J. and Martin, B. R. (1984), Foresight in Science: Picking the Winners, London: Pinter.

[8] Linestone, H.A. (1999), Decision-making for Technology Executives: Using Multiple Perspectives to Improve Performance, Norwood, MA: Artech House.

[9] Loveridge, D. (1996), "Technology and models of the future", PREST Discussion Paper Series, 4 Available from: http://www.personal.mbs.ac.uk/dloveridge/documents/futmodpdf_wp4. PDF.

[10] Martin, B. R., and Johnston, R. (1999), "Technology Foresight for Wiring up the National Innovation System", Technological Forecasting and Social Change, $60(1)$, pp. 37-54.

[11] Martin, B. (2001), "Technology foresight in a rapidly globalizing economy", In: Regional Conference on Technology Foresight for CEE and NIS countries 4-5 April 2001, Vienna, Austria: UNIDO, 2001. Available from: $w$ ww.unido.org/userfiles/kaufmanC/MartinPaper.pdf.

[12] Office of Science and Technology (1993), Realising our Potentials- A strategy for Science, Engineering, and Technology, London: Department of Trade and Industry.

[13] Porter, A. L. et al. (2004), "Technology future analysis: toward integration of the field and new methods", Technological Forecasting and Social Change, 71(3), pp. 287-303.

[14] Rip, A., Misa, T. and Schot, J. (Ed.) (1995), Managing Technology in Society: The Approach of Constructive Technology Assessment. New York: St Martin's Press.

[15] Schot, J. (1998), "Constructive Technolgoy Assessment Comes of Age: The birth of a new politics of technology", In A. Jamison (Ed), Technology Policy Meets the Public (PESTO paper II) (pp. 207-232): Aalborg University.

[16] Slaughter, R. (1995), The Foresight Principle. London: Adamantine Press.

[17] Tegart, G. (2003), "Technology foresight: philosophy \& principles", Innovation: Management, Policy and practice, 5(2), pp. 279-285

[18] Van der Meulen, B. (1999), "The impact of foresight on environmental science and technology policy in the Netherlands", Future, 31, pp. 7-23.

[19] Voros, J. (2003), "A generic foresight process framework", Foresight, 5(3), pp. 10-21 